\title{
Turismo e geografia: perspectivas da Indicação Geográfica (IG) no planejamento territorial
}

\author{
Tourism and geography: perspectives of Geographic Indication (GI) in territorial planning \\ Turismo y geografía: perspectivas de la Indicación Geográfica (IG) en la planificación territorial \\ Licio Valério Lima Vieira \\ Instituto Federal de Educação, Ciência e Tecnologia de \\ Sergipe (IFS), Brasil \\ DOI: https://doi.org/10.18472/cvt.19n3.2019.1497 \\ Redalyc: http://www.redalyc.org/articulo.oa? \\ liciovalerio@gmail.com \\ $\mathrm{id}=115461709016$
}

Roberta Nascimento G Soares

Instituto Federal de Educação, Ciência e Tecnologia de

Sergipe (IFS), Brasil

betanascimento3@gmail.com

Recepción: 28 Septiembre 2017

Aprobación: 20 Diciembre 2019

\section{Resumo:}

O objetivo deste artigo é analisar a relação turismo e geografia a partir da criação de uma Indicação Geográfica (IG). Considera-se a importância neste contexto do planejamento territorial, evidenciado pelas políticas e ações que o conduzem ao fortalecimento da identidade cultural como estratégia de desenvolvimento para o turismo sustentável. Outro aspecto que também deve ser considerado neste contexto refere-se a uma visão planejada do turismo em torno dos territórios interligados em rede, com seus fluxos materiais e imateriais associados aos diversos destinos e suas áreas periféricas que compõem uma região turística. Nesse aspecto, a adoção de Indicação Geográfica (IG) para produtos com forte identidade cultural é um caminho para a valorização dos patrimônios identitários, territórios e cultura regional, fundamentais para criação de serviços e atrativos turísticos competitivos e sustentáveis. A metodologia utilizada para a construção deste artigo tem como base a pesquisa bibliográfica e documental, que compõem as estratégias da revisão sistemática. As IGs associadas ao turismo podem colaborar para a dinâmica de preservação e desenvolvimento sustentável dentro dos territórios, bem como valorizar produtores e produtos com tradição e singularidade, diferenciais enraizados na cultura local, além da ligação com a própria geografia e territorialidade.

Palavras-chave: Turismo, Território, Indicação Geográfica.

\begin{abstract}
:
The aim of this paper is to analyze the relationship between tourism and geography from the creation of a Geographical Indication (GI). In this context, the importance of territorial planning is considered and evidenced by the policies and actions that lead to the strengthening of cultural identity as a development strategy for sustainable tourism. Another aspect that should also be considered in this context refers to a planned vision of tourism around territories interconnected in a network, with their material and immaterial flows associated with the various destinations and their peripheral areas that make up a tourist region. In this regard, the adoption of Geographical Indication (GI) for products with a strong cultural identity is a way to enhance the identity heritage, territories and regional culture, foundations for creating services and competitive and sustainable tourist attractions. The methodology used for the construction of this article is based on bibliographic and documentary research, composing a systematic review strategy. The IGs associated with tourism can collaborate for the dynamics of preservation and sustainable development within the territories, as well as valuing producers and products with tradition and uniqueness, differentials rooted in the local culture, in addition to the connection with the geography and territoriality itself.
\end{abstract}

KEYWORDS: Tourism, Territory, Geographical Indication.

\section{Resumen:}

El objetivo de este trabajo es analizar la relación entre turismo y geografía desde la creación de una Indicación Geográfica (IG). Se considera la importancia en este contexto de la planificación territorial, evidenciada por las políticas y acciones que conducen al fortalecimiento de la identidad cultural como estrategia de desarrollo para el turismo sostenible. Otro aspecto que también debe considerarse en este contexto se refiere a una visión planificada del turismo alrededor de territorios interconectados en una red, con sus flujos materiales e inmateriales asociados con los diversos destinos y sus áreas periféricas que conforman una región turística. En 
este sentido, la adopción de la Indicación Geográfica (IG) para productos con una fuerte identidad cultural es una forma de mejorar el patrimonio de identidad, los territorios y la cultura regional, las bases para crear servicios y atracciones turísticas competitivas y sostenibles. La metodología utilizada para la construcción de este artículo se basa en la investigación bibliográfica y documental, que se componen como estrategias de revisión sistemática. Las IG relacionadas con el turismo pueden contribuir para la conservación y el desarrollo sostenible dentro de los territorios, así como para valorar a los productores y productos con tradición y singularidad, diferenciales arraigados en la cultura local, además de la conexión con su propia geografía y territorialidad.

Palabras clave: Turismo, Territorio, Indicaciones geográficas.

\section{INTRODUÇÃO}

As possibilidades de criação de atrativos turísticos dentro dos territórios através relação turismo/geografia, cultura/patrimônio, homem/produto têm apontado meios para dinamizar o planejamento do setor e estabelecer caminhos para a gestão participativa no desenvolvimento do turismo. A melhor compreensão dessa construção social viabiliza uma diretriz fundamental na atividade turística contemporânea que é o desenvolvimento sustentável.

Fontoura e Andrade (2008) discutem a notável importância adquirida pelo turismo na sociedade contemporânea como prática social, econômica e ecológica, que produz e organiza o espaço, estabelecendo relações de poder e territorialidades que justificam o interesse do fenômeno a partir de um paradigma geográfico.

Raffestin (1993), ao expor o debate sobre conceitos de espaço e território, afirma que tais termos não são equivalentes. $\mathrm{O}$ uso sem critério no campo do turismo acabou esbarrando em análises conflituosas, deturpadas, privando turismólogos e geógrafos de distinções realmente úteis e necessárias. É dentro desta abordagem que o presente artigo traz a reflexão sobre a teoria do espaço turístico de Boullón (2002) e a organização dos territórios em rede adaptados ao turismo, com a finalidade de melhorar a gestão e o planejamento turístico.

A tendência mundial reforça a necessidade de se ressaltar a singularidade de cada território, a fim de oferecer um produto diferenciado, como estratégia para posicionar rotas turísticas em zonas rurais, e incentivar, deste modo, a crescente demanda de turistas que procuram fazer contato com alimentos regionais.

Há inúmeras iniciativas que buscam a diferenciação e valorização dos produtos com especificidade territorial como o fortalecimento dos arranjos produtivos locais e a adoção de Indicação Geográfica (IG), um dos maiores instrumentos de valorização do capital social desenvolvido com base na tradição, terroir, cultura e aspectos geográficos e territoriais.

Segundo Costa e Reubens (2014), os produtores de produtos endógenos e gestores da atividade turística utilizam as indicações geográficas como elemento fundamental na divulgação do produto, construção dos roteiros e elaboração de produtos turísticos que se tornam competitivos por serem diferenciados frente ao mundo globalizado.

os produtos com indicações geográficas são um diferencial na atividade turística, pois trazem na essência elementos que ajudam a manter a cultura local. Trata-se de produção controlada de bens que não permitem a descaracterização da identidade sociocultural e que promove a sustentabilidade das regiōes. (COSTA; REUBENS, 2014, p.39)

A relação de conhecimento e o saber-fazer local marcam a identidade territorial e a capacidade dos atores locais de promoverem um desenvolvimento com características internas. $\mathrm{O}$ resultado dessa produção, que traz, na essência, aspectos da tradição e da geografia, distingue o capital cultural e social, estabelecendo os potenciais de cada território dentro de sua região. No turismo, esses fatores podem fundamentar a criação de atrativos ou produtos turísticos com base na solidariedade, parceria e cooperação, essenciais para criação de redes sociais entre territórios e o exercício da dinâmica do contemporâneo e do tradicional.

$\mathrm{O}$ artigo foi estruturado em três seções, seguido pela metodologia e conclusão. A construção do texto foi realizada com base em revisão teórica com intenção de articular os conceitos de território, identidade 
territorial e indicação geográfica (IG), para mostrar como funciona o desenvolvimento regional associado ao turismo, concluindo com uma visão panorâmica e os possíveis benefícios de uma IG no planejamento territorial. Essas reflexões demonstram a riqueza em abordar esse instituto da Propriedade Intelectual, para o fortalecimento e proteção de patrimônios intangíveis, bem como o fortalecimento da identidade territorial em muitas regiões turísticas do país.

\section{METODOLOGIA}

Esta pesquisa tem como foco principal a identificação e caracterização de produtos com potencial de IG, vinculados ao turismo. Neste contexto, e ao considerar a complexidade do fenômeno turístico associado a produtos locais com intrínseco apelo cultural, histórico e identitário, com reflexo direto na atividade turística, optou-se pela abordagem fenomenológica.

De forma simplificada, com base em Medeiros et al. (2011), a pesquisa fenomenológica começa com a delimitação do tema (fenômeno em estudo), e neste caso Indicação Geográfica e o turismo, depois amostragem, onde se indica preferencialmente grupos de características singulares (os produtores tradicionais) envolvidos em experiências semelhantes, a coleta de dados com enfoque participante e de entrevistas nos cenários onde se encontra o fenômeno, e para finalizar, a análise dos dados deve ser qualitativa. Os resultados são geralmente organizados em categorias, temas e tipologias das experiências.

Quanto aos objetivos, esta pesquisa assenta-se dentro da base de estudos exploratórios e descritivos, pois seu objetivo é proporcionar maior familiaridade com o problema. Para Veal "a pesquisa descritiva é muito comum na área de lazer e turismo por três motivos: o caráter incipiente do ramo, a natureza mutante dos fenômenos estudados e a frequente separação entre pesquisa e ação" (2011, p. 29).

Quanto ao objetivo da pesquisa descritiva, segundo Dencker (1998, p. 124), "em geral procura descrever os fenômenos ou estabelecer relações com as variáveis. Utiliza técnicas padronizadas de coleta de dados como o questionário e a observação sistemática”.

A natureza da pesquisa tem o viés ainda dos estudos aplicados com a abordagem qualitativa que parte da filosofia fenomenológica, para maior compreensão da natureza social que Velho Chico Sergipano apresenta. Já na avaliação de Uwe (2004) a abordagem qualitativa sobre a pesquisa permite ao cientista social maior visão e sensibilidade sobre os estudos empíricos das questões de ordem social em constante mudança (diversidade do ambiente, cultura, história, desigualdades sociais, estilo de vida).

Martins (2006 p. 6) destaca ainda características importantes em relação à pesquisa do tipo qualitativa como sua natureza voltada para a observação do cotidiano, além dos princípios teóricos que são colocados em análise, mas a sua exatidão e quantificação ganham a compreensão relativa, dada a complexidade e processos dinâmicos dos fenômenos sociais.

\subsection{Pesquisa Bibliográfica e Documental}

Quanto aos procedimentos técnicos, na fase inicial, a fundamentação teórica foi realizada a partir da pesquisa bibliográfica, de material já elaborado como a leitura de livros, artigos, dissertações, teses, além de assuntos conexos à temática da pesquisa envolvendo as indicações geográficas e o turismo. A revisão teórica tem como base os clássicos da literatura sobre estudos do turismo como Beni (2001), Boullón (2002), Raffestin (1993), Dias (2003), Rodrigues (1999), e autores que referendam as IGs como Pimentel (2014), Machado (2013), Cerdan (2009), Velloso (2008), Maiorki, Dallabrida (2015) bem como outros que fundamentam o processo de compreensão analítico, crítico e reflexivo da pesquisa. $\mathrm{O}$ trabalho realizado pretende mostrar a relação desses produtos com a terra, o homem e a cultura local, assim como eles se estabelecem na cena do turismo na Rota do Sertão, garantindo, assim, uma visão global do sistema e do planejamento da região. 


\section{RECORTES TEÓRICOS DO TURISMO, DA GEOGRAFIA E DO TERRITÓRIO}

Observa-se, nas pesquisas sobre o turismo que é concebido como ciência social aplicada, que há uma grande tendência pelo viés da análise da geografia. Isso ocorre porque o objeto de estudo deste fenômeno socioambiental e complexo também está relacionado às categorias de base da geografia, como a paisagem, $o$ lugar, a região, o território e o espaço, que, por sua vez, fundamentam a teoria do espaço turístico.

No Brasil, muitos pesquisadores têm se posicionado a favor dessa abordagem devido à complexidade do planejamento turístico e da gestão das políticas públicas em dimensão continental, distribuídos por estados com características próprias de clima, vegetação, economia, sociedade, cultura, história e política.

Referendando Boullón (2002, p. 79) declara que

o espaço turístico é consequência da presença e distribuição territorial dos atrativos turísticos que, não devemos esquecer, são a matéria-prima do turismo. Este elemento é do patrimônio turístico, mais o empreendimento e infraestrutura turística, são suficientes para definir o espaço turístico de qualquer país.

Com base nesse recorte teórico, o turismo só funcionaria quando alinhado à infraestrutura, operacionalização e localização precisa em um território. Através de uma visão sistêmica e metodológica, o autor assinala ainda os componentes desse espaço turístico representado por Zona, Área, Complexo, Centro, Unidade, Núcleo, Conjunto, Corredor, Corredor de traslado e Corredor de Estada, que devem ser trabalhados a partir da visão macro para a micro, de forma interligada.

De acordo com Panosso Netto e Lohmann (2012), a teoria de Boullón é

importante, porque ela se torna uma das bases para o ordenamento dos fluxos turísticos para o estabelecimento das demais ações do setor, uma vez que o planejamento turístico deve iniciar a partir da identificação dos aspectos físicos e geográficos do destino que será desenvolvido (PANOSSO NETTO; LOHMANN, 2012, p. 62).

O debate sobre espaço turístico do geógrafo Fratucci (2009) destaca que é necessário um grande esforço para o entendimento das combinações existentes e possíveis entre as diversas lógicas de apropriação dos espaços turísticos pelos agentes produtores do turismo contemporâneo (turistas, agentes do mercado, poder público, trabalhadores no setor e comunidade receptora em geral) e a aplicação da gestão participativa, para a construção do processo do desenvolvimento sustentável dentro de um destino turístico.

O pesquisador propõe uma revisão emergencial dos modelos nas escalas de atuação políticoadministrativas atuais (nacional, estadual e municipal), consideradas insuficientes para atender às demandas e incorporar as oportunidades geradas pelo turismo a partir da ação dos seus agentes produtores, individual ou coletivamente. Uma das alternativas seria analisar a territorialidade, mais facilmente perceptível nas escalas local e regional.

A ideia de trabalhar a identidade territorial, neste contexto, torna-se uma grande ferramenta na geração de novos itinerários no processo de desenvolvimento do turismo, inclusive na construção de novas territorialidades. As abordagens sobre identidade no processo de transformação contemporâneo e de globalização revelam que os indivíduos não estão mais ligados somente a um código cultural homogêneo, coerente e distintivo, embora haja uma busca incessante para a acomodação de identidade.

Nesse sentido, há uma tendência pelas "novas formas de turismo que buscam um contato mais íntimo com outras culturas e com a natureza e o recorrente discurso da sustentabilidade - que entre outras coisas privilegia a biodiversidade e a diversidade cultural" (FROEHLICH, ALVES, 2007, p. 67).

Para o geógrafo Milton Santos, o território antecede o espaço, embora o espaço geográfico seja mais amplo e complexo, resultado da expressão da história, natureza, relações sociais e produtivas, economia, cultura. O conceito de território, segundo Santos, abrigaria o entendimento como área delimitada, constituída nas relações de poder do Estado com seus atores sociais, que territorializam suas ações com o passar do tempo. $\mathrm{O}$ território surge da dialética de pertença, de lugar como identidade, e também como "palco da proliferação do 
capital, espaço apropriado pelos agentes do capital através da divisão social do trabalho" (SAQUET, 2008, p. 11).

Raffestin (1993) segue essa mesma análise, definindo território como resultado do jogo de poder entre os atores sociais que atuam em um determinado espaço. Em consequência, sua identidade nasce dentro desses limites geográficos, tanto pela apropriação física como simbólica, num processo de construção social de forma sistemática por meio de rede, malha e nós.

Pode ser uma interação política, econômica, social e cultural que resulta de jogos de oferta e de procura, que provém dos indivíduos e dos grupos. Isso conduz a sistemas de malhas, de nós e redes que se imprimem no espaço e que constituem, de algum modo, o território. Não somente se realiza uma diferenciação funcional, mas ainda uma diferenciação comandada pelo princípio hierárquico, que contribui para ordenar o território segundo a importância dada pelos indivíduos e/ou grupos as suas diversas ações. (RAFFESTIN, 1993, p. 151)

Há ainda duas abordagens que complementam a tradução de território: a antropológica, que o define como ambiente de vida, de pensamento da comunidade e, portanto, de construção de identidade; e a sociológica, que revela o seu envolvimento com as raízes históricas, configurações políticas e identitárias, estas ainda pouco exploradas e conhecidas como meio de desenvolvimento econômico (FLORES, 2006, p. 5).

Vale salientar que a interação desses grupos, agentes sociais dentro do território, pode ser um meio propício para desenvolver o processo conhecido como turistificação. Assim como se dá o sistema territorial analisado por Claude Raffestin, o turismo tem em sua estrutura contemporânea a formatação também interligada de forma descontínua, balizada pelas relações hierárquicas, fluxo de mercadoria e informações. Essa organização dentro do plano espacial, caracterizada de ponto a ponto ou nós, com limites e fronteiras.

Fratucci (2009) defende o planejamento do turismo por meio dos territórios-rede como estratégia para avançar as políticas públicas e acompanhar mais de perto a ação e articulação dos agentes produtores do turismo. É importante frisar que o próprio termo território-rede aglutina o conceito e o sistema territorial abordado por Raffestin (1993), só que neste contexto, adaptado ao planejamento turístico.

Sob outro enfoque, é possível perceber esse planejamento a partir das articulações de seus agentes sociais com outros destinos turísticos geograficamente próximos, envolvendo outras localidades circunvizinhas, ampliando, assim, aquele território-rede para a escala regional.

Panosso Netto, Lohmann (2012) ao tratarem sobre planejamento turístico, com base nos estudos de alguns pesquisadores (BARRETO, 2000A; BENI, 2006; COOPER et al., 2001; GOELDNER et al., 2002; MASON, 2003; RUSCHMANN, 1997), destacam alguns fatores que devem ser levados em consideração, como o

planejamento estratégico no desenvolvimento sustentável; valorização do produto turístico como um dos diferenciais do setor; [...] valorização do patrimônio histórico e artístico-cultural; formação e capacitação de mão de obra [...] desenvolvimento de uma forma integrada, considerando-se todos os elementos, de acordo com uma visão sistêmica, em que uma das partes pode afetar o todo e vice-versa (PANOSSO NETTO; LOHMANN, 2012, p. 139).

Essa é a lógica de envolvimento do turismo, enquanto fenômeno que mobiliza economia, rede de informações, transportes, deslocamento de pessoas, oferta de produção direta e indireta. E quando há o aumento do fluxo de turistas, há também uma maior movimentação dos produtores do turismo, incremento do consumo dos produtos locais, artesanato e busca por produtos tradicionais, que carregam a identidade territorial.

O desenvolvimento do turismo acaba induzindo a ampliação do espaço turistificado, levando o turista a explorar outras fronteiras, limites, circular em torno do próprio destino por motivação própria ou por estímulos dos agentes que atuam na região. Por isso, é normal que se criem atrativos diferenciados, dentro do contexto territorial, como uma alternativa também para diminuir os impactos do próprio turismo, gerando ainda o aumento do consumo por tempo de permanência. 
O grande gargalo do setor está na relação de poder dentro do território turistificado e o planejamento das políticas de desenvolvimento. Observa-se uma visão equivocada, determinada pela ação centralizada e hierarquizada do Estado diante dos agentes sociais, produtores do turismo, setores da economia, quando as metas e estratégias alternativas do turismo, segundo Inskeep (1986), deveriam ser racionalmente avaliadas em relação a todos os tipos de benefícios e custos - econômico, sociocultural e ambiental - como parte do processo de desenvolvimento global local, por meio da gestão participativa.

A cidade que serve ao turista, antes precisaria servir aos seus residentes, incluindo boa qualidade de transportes, vias de acesso, sinalização, alimentos e bebidas, água, energia, espaços de lazer, espaço de memória. Sob esta ótica, a complexidade das relações socioambientais e econômicas promovidas pelo turismo ganha maior densidade em escala regional, mas os gestores não podem perder de vista a importância e diferenciação do aprimoramento das políticas públicas em âmbito local, territorial.

Para tornarem-se públicas devem ser frutos de um amplo processo, aberto, democrático e inclusivo que observe e respeite as práticas sociais existentes nas comunidades onde serão implementadas. Políticas decididas nos ambientes fechados de gabinetes de autoridades do governo não podem e não ganham o status de políticas públicas, limitando-se a serem políticas de governo (FRATUCCI, 2009, p. 404).

Por isso, é imperativo liberar-se da dicotomia global x local, para que haja de fato a participação e emancipação plena de todos os agentes sociais envolvidos e garantia de uma gestão democrática em todos os processos do planejamento. Beduschi Filho e Abramovay (2014) destacam justamente a importância da "aprendizagem por interação" entre empresas e os atores locais, que detém o conhecimento tácito de sua localidade, dentro da ótica do planejamento regional.

Em outras palavras, não dá para o hóspede arrumar a casa do anfitrião, sem ao menos conhecê-la direito, e isso ocorre quando as políticas regionais tornam-se modelos locais. Esse olhar de quem vem de fora deve ser guiado pelos donos da casa, pois são eles que mostrarão os seus potenciais, suas belezas, os melhores cenários e seus desafios. Os autores completam que "a política territorial não consiste mais em redistribuir recursos e riquezas já criadas e existentes, mas, ao contrário, em despertar os potenciais para a criação de riquezas, iniciativas e coordenações novas" (BEDUSCHI FILHO; ABRAMOVAY, 2014, p. 44).

\section{IDENTIDADE CULTURAL, INDICAÇÃO GEOGRÁFICA (IG) E TURISMO}

O processo de globalização, promovido pela revolução da comunicação em rede e do próprio capitalismo, foi determinante para o avanço dos transportes e do turismo. Paradoxalmente, essa transformação permitiu a construção de um mundo global, sem fronteiras, com novos padrões culturais (CAPRA, 2005).

Neste contexto global, abriu-se um caminho para que o turista explorasse territórios que transmitissem o senso de pertença, com seus produtos artesanais, identidade cultural, histórica e geográfica, com grande valor social agregado em torno de pequenas comunidades, arranjos produtivos locais e agricultura familiar.

Há, de forma evidente, um consumo padronizado, disponível nas prateleiras, que supre e induz as demandas diárias, através do apelo à praticidade, conforto, custo, mobilidade etc. Mas há, também, o sentimento contemporâneo, que insiste na volta às origens; que deseja consumir um produto ou serviço diferenciado, no qual revele sua identidade, história, geografia; que faça parte ou valorize o comércio solidário, a sustentabilidade e todas as riquezas das tradições culturais.

Murilo Flores destaca que

essa redescoberta do sentimento de pertencimento ao lugar é reforçada por diversas proposições, de diferentes autores que, contestando as teorias de aculturação que ocorreria com o processo de modernização (ou de globalização), sugerem que as novas construções identitárias têm ocorrido com um reencontro com tradições culturais (CARNEIRO, 1997; BILLAUD,1996; JOLLIVET, 1984, JEAN, 1997 apud FLORES, 2006, p. 6). 
Dentro desse contexto, a relação entre territórios turísticos e arranjos produtivos locais, envolvendo a agricultura familiar, quando bem ordenados por políticas públicas, pode aglutinar qualidades e vantagens para a inovação e competitividade dos produtos e dos serviços locais, além de outros mercados e surgimento de novas habilidades e capacidades dos atores sociais. Vale destacar os espaços com apelo para o desenvolvimento do turismo rural, agroturismo, turismo de propriedades rurais, turismo sertanejo e turismo gastronômico.

Para o turismo, a abordagem dos sistemas produtivos locais é considerada vantajosa. Costa e Souto-Maior (2009) destacam que, haja vista a necessidade de cooperação entre os participantes da cadeia produtiva para efetivar os destinos turísticos e a competitividade com outros aglomerados vizinhos a que se considerar os arranjos produtivos locais. Esses sistemas podem se configurar de diferentes formas através de clusters, distritos industriais, arranjos produtivos locais (APL) e redes. De forma geral, todos os modelos dizem respeito ao sistema de produção geograficamente aglomerado que convertem a proximidade em vantagem competitiva devido à relação sinérgica e concentração territorial.

Fica clara a necessidade de fomentar o turismo por meio da cooperação nas localidades, para que se possa prestar um serviço de qualidade. No Brasil, isso ganha relevância na medida em que o diagnóstico do turismo, exposto no Plano Nacional de Turismo (MTUR, 2003), revela a falta de estruturação da cadeia produtiva do setor como uma causa para sua baixa competitividade.

A perspectiva contemporânea do debate em torno do planejamento do turismo no Brasil tem avançado desde a formulação do sistema turístico regional, com a implementação do Programa de Regionalização do Turismo - Roteiros do Brasil, do Plano Nacional do Turismo 2003-2007 e com o próprio programa dos Destinos Indutores do Desenvolvimento Regional, pesquisa encomendada pelo MTur à Fundação Getúlio Vargas, para medir o grau de competitividade e qualidade dos destinos. Neste plano, o foco é o desenvolvimento turístico sustentável e o planejamento coordenado e participativo dentro dos territórios.

Algumas políticas públicas de estímulo à cooperação no turismo são encontradas na agenda do país, como o projeto Rede de Cooperação Técnica para a Roteirização, promovido pelo Sebrae, em parceria com o Ministério do Turismo. Na teoria, o projeto propõe trabalhar o uso racional do território e seus recursos a partir dos interesses coletivos para posteriormente pensar na articulação regional e a roteirização, que segundo a definição apresentada pela SEDETEC/EMSETUR (2009), é uma forma de organizar e integrar a oferta de turismo de uma região, criando produtos lucrativos e comercialmente duradouros.

Em outras palavras, pode ser um meio de conferir realidade turística. Por isso, desde 2007, através do convênio com o Ministério do Turismo, a SEDETEC/EMSETUR uma espécie de cartilha com o plano de Regionalização do Turismo: Roteiros do Brasil no Estado de Sergipe para aplicar as estratégias e diretrizes definidas pelo Programa de Regionalização Roteiros do Brasil, com o objetivo de orientar a população e todos os segmentos envolvidos com o turismo.

De modo geral, o plano tenta se adequar aos potenciais roteiros de Sergipe e segue os modelos operacionais e metodológicos formulados pelo Mtur e pelo Plano Nacional do Turismo de outras regiões. Desde a dedicatória, o projeto revela que "a proposta de um desenvolvimento sustentável para o Estado passa, além das condições ambientais, pelo respeito à identidade cultural dos territórios e pela inclusão social” (SEDETEC/ EMSETUR, 2009).

Vale ressaltar que a identidade cultural do território turistificado é uma grande ferramenta para o fomento dos produtos turísticos, formados pelo conjunto de atrativos, equipamentos e pelos serviços turísticos propriamente ditos. Esse conjunto de atrativos pode e deve incorporar os produtos com IG para fortalecer o turismo, já que, via de regra, acolhem bens e patrimônios intangíveis como a gastronomia, cultura local e o artesanato. Isso fica bem claro na região da Serra Gaúcha, no Vale dos Vinhedos, onde os vinhos e outros produtos receberam notoriedade da IG e maior valor agregado nos atrativos turísticos, bem como a Uva Goethe, na região de Santa Catarina com festivais gastronômicos e movimento Slow Food, são dois exemplos de como uma IG pode contribuir para o desenvolvimento turístico local. 
Ao se voltar ao entendimento das teorias de Boullón (2002), convém ressaltar que a matéria-prima do turismo é o próprio atrativo turístico, que "é o recurso natural ou cultural formatado em negócio, que atenda todas as especificações necessárias para comercialização e recepção de turistas, com responsabilidade social, ambiental e cultural" (SEBRAE/SP 2016, p. 10). Nesta relação de apropriação do espaço, onde os atrativos (atividades de aventura, feiras de artesanato, feiras de gastronomia, unidades de conservação UCs, fazendas históricas, museus, igrejas, balneários) podem estar aglomerados ou não, configuram-se novos territórios.

A proposta do Programa Nacional de Regionalização seria incluir os municípios por meio de suas qualidades particulares. Se um município, por exemplo, está voltado para a "atividade agropecuária, fornecendo leite, queijo e derivados, organizados ou não em APL, poderia integrar-se à rede de desenvolvimento regional, transformando-se em uma unidade de apoio ao roteiro turístico do município vizinho", caracterizado por um itinerário com um ou mais elementos que lhes conferissem identidade (SEDETEC/EMSETUR, 2009, p. 37).

A construção social de um território, portanto, pode ou não ser associada a estratégias de valorização de produtos locais, de forma diferenciada, se a eles se associa os fatores que diferenciam o território, ou melhor, dizendo, os fatores que lhe são específicos. Esses fatores, na maioria das vezes, são formados pela interação entre o patrimônio natural e o patrimônio histórico-cultural presentes no território (FLORES, 2006, p. 9)

A proposta de IG para produtos com identidade cultural pode viabilizar uma nova alternativa para a valorização, proteção e desenvolvimento sustentável de muitas comunidades do campo. Normalmente esses produtos envolvem notoriedade, reconhecimento popular adquirido pela tradição e singularidade, como diferenciais do produto efetivamente enraizados na cultura local, dada a sua ligação com a geografia e territorialidade.

Assim como em muitos países da Europa, o Brasil tem criado meios de certificar os produtos marcados pela sua territorialidade, favorecendo o desenvolvimento regional. Uma das IGs mais marcantes e com profundo impacto no turismo está localizada na região sul, referindo-se aos “produtos coloniais" produzidos pelos imigrantes na serra gaúcha e os vinhos do Vale dos Vinhedos, que mantêm tradições, mesmo associados a novos conhecimentos agregados aos seus processos produtivos incentivando o turismo rural, turismo de experiência e ecoturismo.

A experiência com as vinícolas gaúchas que obtiveram a Indicação de Procedência (IP) resultou na valorização das terras (de 200\% a 500\% do valor, em Bento Gonçalves) e elevação da autoestima da população, que hoje se preocupa em manter o foco em suas tradições. As vinícolas também passaram a investir alto em tecnologia e no planejamento do turismo, mercado que reforçou a notoriedade da enogastronomia e cultura italiana. Hoje, a Serra Gaúcha tornou-se uma grande atração turística nacional pela sua capacidade de entretenimento e infraestrutura, agregando atrações de outros municípios daquela região.

Segundo Murilo Flores (2006, p.10) muitos autores alertam para a compreensão de que muitas localidades, aparentemente, não possuem um patrimônio histórico-cultural-geográfico reconhecido. No entanto, ele afirma que as sociedades podem ser estimuladas a explorar seu potencial territorial e o saber-fazer local, num processo de construção coletiva cujo resultado poderia ser a diferenciação de produtos com qualidade para o mercado, agregando valor para o turismo.

Normalmente, observa-se a construção de uma identidade de caráter sociocultural e econômica que possibilita a formulação de uma estratégia competitiva ancorada no território, que comumente pratica o agroturismo, turismo rural e turismo gastronômico.

Los establecimientos han hecho un importante trabajo de conciencia reflexiva sobre sus producciones y saberes, otorgándoles un valor social y pudiendo interpretar el alcance que tiene este ejercicio en términos de "identidad cultural". Asimismo, se evidencia el desarrollo de una actividad turistica más formalizada, tendiente hacia la profesionalización en la gestión integral y la comercialización. (CORDISCO, 2013, p. 18) 
Muitos pesquisadores associam a IG ao desenvolvimento territorial devido ao seu enraizamento sociocultural com os produtos e local de origem. Na visão de Cerdan (2009) a IG mostra-se importante ao valorizar as particularidades de diferentes produtos de diferentes regiões, valorizando territórios através da proteção de seus patrimônios e também da biodiversidade cultural das comunidades.

Cria um fator diferenciador para produto e território, que apresentam originalidade e características próprias. Assim, as indicações geográficas não diferenciam, portanto, somente os produtos ou serviços, mas os territórios. (CERDAN, 2009, p. 281)

Niederle (2011, p. 98) reforça também que "as IGs constituem uma noção genérica que faz sentido para diferentes contextos e atores sociais. De fato, sua fortaleza reside no modo flexível com que permite aos indivíduos e organizações mobilizarem os recursos materiais e simbólicos peculiares de cada território".

É preciso ter esta noção, pois a obtenção da IG, por si só, não confere a sustentabilidade de um produto, ao contrário de uma rota turística bem articulada com suas potencialidades contribui para o ensejo de políticas públicas voltadas para o desenvolvimento socioeconômico e cultural da localidade. Dentro do turismo, a IG funciona como uma forma de valorização dos atrativos, com a comercialização de produtos com maior apelo cultural, diferenciação, segurança para o turista que vai consumir um produto com certificação, conhecimento sobre produção, envolvendo manejo sustentável, proteção de cultura e patrimônios locais, envolvimento com as comunidades locais, agricultura familiar etc.

\section{INDICAÇÃO GEOGRÁFICA (IG) COMO PROTEÇÃO DO PRODUTO}

Há uma longa trajetória histórica sobre o aparecimento de produtos com Indicação Geográfica no mundo. De acordo com o MAPA (2014), isso ocorreu de forma gradativa por produtores e consumidores, ao perceberem qualidades específicas de produtos que provinham de determinados lugares. Havia na origem desses produtos uma relação intrínseca envolvendo território, condições socioambientais, históricas, relação homem-natureza e herança de um saber-fazer cultural distinto.

Há registros de indicações geográficas citadas pela Bíblia, que mencionam na antiguidade o cedro do Líbano (REIS, V, 6; CÂNTICOS, III, 9) e os vinhos de En-Gedi (CÂNTICOS, I, 14), e mesmo na Roma e na Grécia Antiga, muitos produtos eram reconhecidos e diferenciados pela sua origem como o mármore de Paros, o bronze de Corinto, o mel da Sicília, as amêndoas de Naxos, os vinhos de Corinto, os tecidos de Mileto e Sídon, as espadas de Cálcis e as estatuetas feitas de terracota de Tânagra (BERTOZZI, 1995; ALMEIDA, 2001; 2010; VIVEZ, 1943; CARVALHO, 2009 apud COSTA; REUBENS, 2014).

Bruch e Dewes (2013) destacam que neste período muitos produtos de corporações ganhavam selos com nome da cidade ou da localidade, como forma de proteção contra falsificação, resguardar a reputação e demarcar sua origem. Só a partir do séc. XVIII que a certificação de uma IG ganhou dimensão internacional. A primeira intervenção estatal para proteção dos produtores, mercado e consumidores ocorreu em Portugal, em 1756, em virtude da queda das exportações do Vinho do Porto para Inglaterra, instituída por Marques de Pombal (MAPA, 2014).

A adoção de uma IG para um produto veio garantir não só o reconhecimento e valorização de sua região de origem, como de seu território, de características peculiares e fator de diferenciação entre produtos de um mesmo segmento, atuando sobremaneira como forma de proteção de seus consumidores e benefícios comerciais. É por isso que, via de regra, é do interesse de produtores e agentes a organização para valorizar as características de sua região, dos produtos de sua terra, e a mobilização do direito de propriedade intelectual, para obtenção da IG.

O estado da arte tem definido a IG como o caminho para a valorização de produtos que assumem os patrimônios identitários de seus territórios e a cultura regional de produtos marcados por sua geografia e saber-fazer exclusivo. Como propriedade intelectual do tipo industrial, coletiva e exclusiva a produtores de 
determinado local, um dos seus benefícios é proteger seus consumidores, manter a cultura local, promover o turismo, a abertura do comércio, e o estímulo do agroturismo (GOLLO; CASTRO, 2007; PIMENTEL, 2013; BOECHAT; ALVES, 2011; KAKUTA et al., 2006 apud MAIORKI; DALLABRIDA, 2015).

A Identidade Geográfica assume desta forma, grande papel socioeconômico e cultural no cenário contemporâneo mundial do comércio. Em movimento contrário à produção em grande escala industrial, massiva e padronizada, a IG é uma certificação que, em sua essência, tem salvaguardado a sobrevivência dos produtos que envolvem tradição, patrimônio territorial e, sobretudo, as produções de ordem artesanal, difundidas geralmente dentro da agricultura familiar e nos pequenos arranjos produtivos, estimulando a autoestima de sua comunidade e evitando o movimento de migração para grandes centros.

Maiorki e Dallabrida (2015) fundamentam a discussão sobre o tema Indicação Geográfica em torno de questões essenciais como a concepção de território, identidade e desenvolvimento territorial. Há, dentro deste aspecto, uma semelhança sobre a visão aplicada às políticas públicas no turismo, como forma de fomentar os atrativos dentro de uma rota ou destino.

Reconhecendo a sua importância para o fortalecimento da agricultura e manutenção dos produtos do campo, o Ministério da Agricultura tornou-se uma das instâncias de fomento de atividades e ações com suporte técnico aos processos de obtenção de registro de IG através da Coordenação de Indicação Geográfica de Produtos Agropecuários (CIG), Coordenação Geral de Qualidade (CGQ)/Departamento de Desenvolvimento de Cadeias Produtivas e Produção Sustentável (DDCP), órgãos da Secretaria de Mobilidade Social, do Produtor Rural e do Cooperativismo (SMC).

No Brasil, a lei 9.279 de 14 de maio de 1996 define os direitos de propriedade industrial, e, especificamente, os artigos 176 a 182, regulamentam a IG. O registro dos produtos é realizado pelo Instituto Nacional de Propriedade Industrial (INPI), que os classifica como Indicação de Procedência e Denominação de Origem.

Bruch (2008, p. 10) ressalta que a IG é "mais que um instituto jurídico ou um objeto de marketing, é a Indicação Geográfica uma possibilidade de se garantir a sustentabilidade de uma determinada região, sem que isso implique sua transformação em um pólo industrial ou uma região de monocultura”.

O Brasil tem uma posição insignificante na aquisição de IGs, se comparado a qualquer país da Europa. Apesar disso, na última década, o número de registros de IGs concedidos pelo INPI chama atenção de pesquisadores pelo crescimento expressivo. Vale lembrar que a lei que criou as IGs é de 1996, mas só após seis anos foi reconhecida a primeira IG brasileira, a do Vale dos Vinhedos, em 2002.

Até o ano de 2010, somente mais cinco IGs haviam sido certificadas, revelando a morosidade e a burocracia do processo para o reconhecimento de produtos tradicionais, em sua maioria de base agroalimentar mapeados em APLs e na base da agricultura familiar. Entre 2011 e 2012, no entanto, esse número saltou para mais 18, e hoje, já são 55 IGs espalhadas por várias regióes do país, 45 delas por IP e 10 por DO. Vale ressaltar que os Estados que mais obtiveram IGs reconhecidas desde o início da lei foram o Rio Grande do Sul (arroz, vinhos, carne, couro, doces) e Minas Gerais (cafés, biscoito, peças de estanho, cachaça, queijos da Canastra e do Serro, própolis verde), dez e nove registros, respectivamente, com base em informações disponíveis no portal do INPI.

As regiões Norte e Centro-Oeste do país, apesar do grande potencial, da riqueza e diversidade histórica e biocultural são as que menos têm IGs reconhecidas, seguido do Nordeste que começa a reverter o quadro, em busca de estratégias de cooperação para identificar produtos com potencial de IG. Em relação aos novos depósitos para requerer o reconhecimento de IG, o estado que mais avançou foi o Paraná com oito pedidos, segundo dados do INPI. A Tabela 1 revela a distribuição de IGs pelas cinco regiões do país. 
TABELA 1

IGs reconhecidas nas regiões brasileira

\begin{tabular}{l|c|c}
\hline IG pelas Regiões do País & Indicação de Procedência & Denominação de Origem \\
\hline Norte & 2 & 0 \\
\hline Nordeste & 10 & 3 \\
\hline Centro-Oeste & 5 & 0 \\
\hline Sudeste & 15 & 5 \\
\hline Sul & 13 & 2 \\
\hline Total & 45 & 10 \\
\hline
\end{tabular}

Fonte: Elaborado pelos autores a partir de dados do INPI (2017)

As matérias informativas postadas no site do INPI destacam que há um esforço para divulgar cada vez mais as atribuições do instituto e a importância da propriedade intelectual (PI). No dia 10 de março de 2016, o INPI, vinculado ao Ministério do Desenvolvimento, Indústria e Comércio Exterior (MDIC), firmou um acordo de cooperação técnica com o Serviço Brasileiro de Apoio às Micro e Pequenas Empresas (SEBRAE), válido por três anos, até 2019. O objetivo é ampliar o acesso à proteção de patentes e ao registro de marcas e de indicações geográficas para tornar os pequenos negócios mais competitivos e inovadores, estimulando o desenvolvimento de tecnologias e o uso das informações tecnológicas contidas em patentes (INPI, 2016).

A crescente procura e interesse pela IG é uma realidade que tende a ser consolidada devido às novas necessidades de consumo (segurança, qualidade, origem e sustentabilidade). A maior parte das IGs concedidas no Brasil são direcionadas para alimentos e bebidas, e o grande desafio é inserir procedimentos técnicos e normas, sem que descaracterize o sistema de produção e reverta-se em melhoria a longo prazo para os produtores. Por isso, a necessidade da orientação dos estudos de antropologia, sociologia, entre outras disciplinas, bem como a união com instituições de pesquisa, universidades para o acompanhamento do processo de construção da IG.

Reconhecidamente, a indicação geográfica atua na indução do comércio dos produtos tradicionais à medida que permite o acesso entre mercados interno e externo, pois, normalmente os produtos que obtém o registro passam por uma reavaliação técnica para o aperfeiçoamento dos métodos de produção e sustentabilidade dos recursos utilizados. Em suma, ela garante não só uma maior confiança do consumidor (turistas), que sabe que está levando produtos com identidade e indicativos de seu terroir, como se reverte em benefícios sociais e culturais para produtores de regiões desfavorecidas com a geração de renda e maior valor agregado.

Um caso bastante emblemático no mundo, de acordo com Cerdan et al $(2014$, p. 48) é o da região de Champagne, na França, que antes era considerada uma região carente, e a dinâmica da IG associada ao planejamento e fortalecimento da governança local, transformou sua realidade de forma muito positiva. A partir de suas particularidades, produção de uva, solo e método "champenoise", seu produto não só elevou o nome da região, como também a sua economia, abrindo espaço para outros segmentos como turismo, gastronomia.

Isso ocorreu também no Vale dos Vinhedos, no RS, mais tarde com a uva Goethe, em SC, mas, apesar de todos os ganhos comprovados das IGs, a maioria dos planos de ação para fomentar o desenvolvimento de certificação ainda é escasso, com grande necessidade de uma visão sistêmica e interdisciplinar a respeito do tema. Niederle (2011) afirma que a construção de uma IG é uma inovação que ocorre em um contexto interativo, devendo envolver o esforço de apoio técnico, institucional e a participação direta da comunidade.

Isso significa que, ao invés do foco no empreendedor individual, a formação deste mecanismo exige uma abordagem em termos de redes sociais ou sociotécnicas. Em ambos os casos, a análise volta-se para as ligações entre distintos atores, a 
circulação de recursos, os processos de tradução e o modo como este tipo de estrutura favorece a inovação (NIEDERLE, 2011, p. 101)

Em Sergipe há somente um produto com indicação geográfica, que é a renda irlandesa de Divina Pastora, renda de agulha em lacê, com titularidade da Associação para o Desenvolvimento da Renda Irlandesa de Divina Pastora (ASDEREN), que recebeu certificação em 26 de dezembro de 2012. Foi a primeira renda do país a receber certificação, envolvendo longo processo de estudos e mobilização de políticas públicas para sua obtenção desde 2008, quando recebeu o registro de patrimônio cultural imaterial do Brasil pelo IPHAN. O próprio trabalho do instituto do patrimônio facilitou o caminho para o reconhecimento da IG, que também teve o apoio do Sebrae, que na oportunidade fez um mapeamento de outros produtos com potencial de IG em Sergipe.

Dias (2016) destaca que as IGs são responsáveis pelo desenvolvimento da maior parte do território europeu, através do reconhecimento do capital social e econômico dos produtos endógenos. No Brasil, esse instituto carece de maior percepção e acúmulo de pesquisas, sobretudo em torno de casos particulares para avaliação dos seus reflexos positivos e impactos na comunidade. Para o autor:

É de fundamental importância enriquecer o debate das indicações geográficas em razão da biodiversidade produtiva e da democratização econômica que proporciona, superando o modelo predominante da agricultura tradicional, baseado no mercado de comodities agrícolas. Vale ressaltar que o instituto jurídico econômico das indicações geográficas coadunam-se com as políticas públicas voltadas à redução das desigualdades regionais e sociais do país (art. 170, VII da CRFB). (DIAS, 2016, p. 179)

O MAPA vê a IG como uma ferramenta de desenvolvimento regional e territorial, e suas vantagens estão relacionadas com a capacidade de transformação de pequenas comunidades e inclusão social e econômica. Suas principais vantagens estão associadas à proteção do produto, preservação do patrimônio, bem como acesso à novos mercados e maior confiança dos consumidores.

\section{CONSIDERAÇÕES FINAIS}

O turismo enquanto fenômeno transformador da sociedade mobiliza economia, rede de informaçóes, transportes, deslocamento de pessoas, oferta de produção direta e indireta. Está implícito que o aumento do fluxo de turistas reflete numa maior movimentação dos produtores do turismo, do incremento do consumo dos produtos locais, artesanato, e na busca por produtos tradicionais, que carregam a identidade territorial.

Pensar o planejamento turístico a partir dos territórios, por meio da comunicação em rede, observando o processo de construção social participativa torna-se o caminho para o fortalecimento de identidades culturais e capital social. Ordenar as políticas públicas para o bom funcionamento dos territórios turísticos através da valorização dos arranjos produtivos locais, comprovadamente pode gerar estratégias e vantagens competitivas para os produtos e serviços locais, incentivando habilidades e capacidades dos atores sociais. $\mathrm{O}$ estímulo de uma comunidade nas decisões participativas na governança local colabora para fortalecimento do planejamento regional do turismo.

A identificação de produtos com potencial de IG associados às perspectivas do turismo poderá servir ainda como subsídio para reforçar a importância socioeconômica e cultural de uma certificação do Instituto Nacional de Propriedade Industrial (INPI) para os produtos tradicionais. Como resultado, pretende-se gerar um novo olhar a respeito dos produtos tradicionais, aprendizagem, quebra de paradigmas, e novas estratégias e subsídios para a comunidade aperfeiçoar seus produtos dentro das rotas turísticas com potencial para valorizar a gastronomia e produtos artesanais.

A proposta de Indicação Geográfica para produtos com apelo identidade cultural pode se tornar uma estratégica dinâmica para a valorização, preservação e desenvolvimento comercial sustentável de muitas comunidades rurais, que tem como base a agricultura familiar e os arranjos produtivos locais. Normalmente 
esses produtos envolvem notoriedade, reconhecimento popular - adquirido pela tradição - e singularidade, como diferenciais do produto efetivamente enraizados na cultura local, além da ligação com a própria geografia e territorialidade.

\section{REFERÊNCIAS}

BRUCH, Kelly L.; DEWES, Homero. 11. A relação entre os signos e o vinho na história. Revista Jurídica do Cesuca, v. 1, n. 1, p. 151-173, 2013.

CAPRA, Fritjof. As conexões ocultas: ciência para uma vida sustentável. Tradução Marcelo Brandão Cipolla. São Paulo: Cultrix, 2005.

CERDAN, Claire Marie; BRUCH, Kelly Lissandra; SILVA, Aparecido Lima da; COPETTI, Michelle; FAVERO, Klenise Chagas; LOCATELLI, Liliana. Indicação Geográfica de produtos agropecuários: importância histórica e atual. In: PIMENTEL, Luiz Otávio (Org.) Curso de propriedade intelectual \& inovação no agronegócio: módulo II, indicação geográfica. Florianópolis: Ministério da Agricultura, Pecuária e Abastecimento (MAPA)/ FUNJAB, 2014, v. 4, p. 32-58.

CERDAN, Claire. Valorização dos produtos de origem e do patrimônio dos territórios rurais no sul do Brasil: Contribuição para o desenvolvimento territorial sustentável. Política \& sociedade, v. 8, n. 14, p. 277-300, 2009.

CORDISCO, Marina et al. Cultura, identidad y territorio: reflexiones para el desarrollo de una estrategia de diferenciación del servicio agroturístico en emprendimientos de un Grupo de Cambio Rural (INTA) del partido de Coronel Suárez (Buenos Aires). Mundo agrario, v. 14, n. 27, 2013.

COSTA, Coelho; REUBENS, Ewerton. As Indicações Geográficas (IGs) como elementos fortalecedores para a atividade turística. Revista Turismo: estudos e práticas, v. 3, n. 1, 2014.

DENCKER, Ada de Freitas Maneti. Métodos e técnicas de pesquisa em turismo. Futura, 1998.

DIAS, José Carlos Vaz. Propriedade intelectual e os dez anos da lei de inovação: conflitos e perspectivas. Gramma, 2016.

FLORES, Murilo. A identidade cultural do território como base de estratégias de desenvolvimento - uma visão do estado da arte. Contribuição para o Projeto Desenvolvimento Territorial Rural a partir de Serviços e Produtos com Identidade - RIMISP. Março, 2006, p. 3-47.

FONTOURA, Leandro M.; ANDRADE, Sabrina de A. Turismo e geografia: O Planejamento Territorial do Turismo. Anais... II Fórum Internacional de Turismo Do Iguaçu, junho de 2008. Foz do Iguaçu - Paraná

FRATUCCI, A. C. Refletindo sobre a Gestão dos Espaços Turísticos: perspectivas para as redes regionais de turismo. Turismo em Análise, v.20, n.3, dezembro 2009.

FROEHLICH, José Marcos; ALVES, Heberton F. Inocêncio. Novas identidades, novos territórios: Mobilizando os recursos culturais para o desenvolvimento territorial. Revista Extensão Rural, v. 14, p. 65-90, 2007.

INPI. Pedidos de indicação geográfica concedidos e em andamento. Modificado pelo CGCOM em 30 de março de 2017. Disponível em: http://www.inpi.gov.br/menu-servicos/indicacao-geografica/pedidos-de-indicacao-geog rafica-no-brasil Acesso: 30 de março 2017.

INPI. Pequenos negócios terão incentivo para proteger patentes, marcas e IGs. 11 de março de 2016. Disponível em:<http://www.inpi.gov.br/noticias/pequenos-negocios-terao-orientacao-e-incentivopara-proteger-patentes-marcas-e-indicacoes-geograficas>; Acesso em: 10 de fev. 2017.

INSKEEP, Edward. Environmental planning for tourism. Annals of Tourism Research, v. 14, n. 1, p. 118-135, 1987.

MAIOR, Alice P. Souto; COSTA, Helena A. Sistemas produtivos locais em turismo: relacionamentos estratégicos e aglomeração territorial como vantagens competitivas. Revista Acadêmica Observatório de Inovação do Turismo, v. 1, n. 1, (2008). P. 13-a,.

MAIORKI, Giovane J.; DALLABRIDA, Valdir R. A indicação geográfica de produtos: um estudo sobre sua contribuição econômica no desenvolvimento territorial. INTERAÇÕES, Campo Grande, v. 16, n. 1, p. 13-25, jan./jun. 2015. 
MARTINS, Lígia M. As aparências enganam: divergências entre o materialismo histórico dialético e as abordagens qualitativas de pesquisa. Anais da Reunião anual da ANPED, v. 29, p. 1-17, 2006.

NIEDERLE, Paulo. Compromissos para a qualidade: projetos de indicação geográfica para vinhos no Brasil e na França. Tese de Doutorado. Universidade Federal Rural do Rio de Janeiro, 2011.

PANOSSO NETTO, Alexandre; LOHMANN, Guilherme. Teoria do Turismo: conceitos, modelos e sistemas. 2ed. São Paulo: Aleph, 2012.

PANOSSO NETTO, Alexandre; NECHAR, Marcelino Castillo. Epistemologia do turismo: escolas teóricas e proposta crítica. Revista Brasileira de Pesquisa em Turismo, v. 8, n. 1, p. 120-144, 2014.

PORTAL BRASIL. Produtos com registro de identificação geográfica se destacam no setor agropecuário, 2014. Disponível em: <"http://www.brasil.gov.br/governo/2012/01/produtos-com-registro-de-identificacaogeografica-se-destacam-no-setor-agropecuario">. Acesso em 15 de maio 2016.

RAFFESTIN, Claude. 1993. Por uma Geografia de Poder. São Paulo: Ática, 1980.

SAQUET, Marcos A.; DA SILVA, Sueli S. MILTON SANTOS: concepções de geografia, espaço e território/milton santos: geography conceptions, space and territory. Geo UERJ, v. 2, n. 18, p. 24 à 42, 2011.

SEBRAE/SP. 1. Entendendo o Atrativo Turístico. Cadernos de Atrativos Turísticos. São Paulo: SEBRAE, 2016. 1 a 168. Disponível em: <http://www.bibliotecas.sebrae.com.br/chronus/ARQUIVOS_CHRONUS/bds/ bds.nsf/e6ab735ac11e71802d2e44cbce6d63f4/\$File/SP_cadernodeatrativosturisticoscompleto.16.pdf.pdf>; Acesso em 22 abr 2017.

SERGIPE. Secretaria de Estado do Desenvolvimento Econômico da Ciência e Tecnologia e do Turismo. Empresa Sergipana de Turismo. Regionalização do Turismo: roteiros do Brasil no Estado de Sergipe - Aracaju: SEDETEC/EMSETUR, 2009. (Convênio Ministério do Turismo/Sociedade do Cangaço nº 963/2007), p. 100.

UWE, Flick. Uma introdução à pesquisa qualitativa. Porto Alegre: Artmed, 2004.

VEAL, A.J. Metodologia de Pesquisa em Lazer e Turismo. São Paulo: Aleph, 2011.

BRASIL. Plano Nacional de Turismo: diretrizes e metas e programas 2003-2007. Brasília: Ministério do Turismo (MTUR), 2003.

BRUCH, Kelly L. Indicações geográficas para o Brasil: problemas e perspectivas. Propriedade intelectual: gestão do conhecimento, inovação tecnológica no agronegócio e cidadania. Florianópolis: Fundação Boiteux, 2008.

\section{ReFERENCIAS}

BOULLÓN, Roberto C. Planejamento do espaço turístico. Tradução de Josely Vianna Baptista. Bauru, SP: EDUSC, 2002.

\section{ReFERENCIAS}

BEDUSCHI FILHO, Luiz C.; ABRAMOVAY, Ricardo. Desafios para o desenvolvimento das regiões rurais. Nova Economia, v. 14, n. 3, 2009, p. 35 a 70.

\section{REFERENCIAS}

PIMENTEL, Luiz Otávio (Org.). Curso de propriedade intelectual \& inovação no agronegócio: módulo II, indicação geográfica. Florianópolis: Ministério da Agricultura, Pecuária e Abastecimento (MAPA)/ FUNJAB, 2014, v. 4, p. 32-58. 